\title{
Reflections on Revitalization of Macao's Animation Industry and Reform of Talent Training Mode
}

\author{
Ma Nan \\ Macau University of Science and Technology \\ Macau, China
}

\begin{abstract}
Macao's modern animation industry, which has no self-owned brand and lacks higher professional education settings, is not innovative enough, The current situation is unsatisfactory. In fact, Macao's co-existing cultural elements are integrated and flourished together in a variety of ways. If the opportunity of revitalization can be seized with a deep and fertile animation industry and higher education soil, a great contribution will be made. Based on the investigation of Macao's animation industry and talent training, this paper puts forward the reform methods, takes a serious view of and deeply studies various development strategies, which has certain guiding significance for improving the city image of Macao, the training of Macao's animation designers, and the creation of related excellent animation works.
\end{abstract}

Keywords-Macao's animation industry; talent training; animation education; cultural element; opportunity

\section{INTRODUCTION}

Since the Jiajing and Longqing Periods of the Ming Dynasty, the government of the Ming Dynasty allowed Portuguese people to rent houses in Macao for living on the premise of recognizing that Macao was China's territory and accepting supervision and management. In the principle of "building cities, setting officials and governing by county level", Macao was under the jurisdiction of Xiangshan County, Guangdong Province. As rented by Portuguese in 1557, Macao became a bridgehead for Westerners to land in China. In the 400 years of strong implantation of Western culture, the cultural characteristics of the convergence, multi-integration and harmonious coexistence of Chinese and Western cultures have gradually formed. Western Christian culture of ethnic beliefs represented by Portuguese and traditional Chinese culture represented by Guangdong and Fujian provinces root and sprout, interact with each other and coexist here.

At the 29th meeting of UNESCO World Heritage Centre, the historic urban area of Macao, China, was officially listed as China's 31st World Heritage Site. This ancient urban area (formerly known as Macao Historic Architectural Complex) consists of 22 buildings and 8 adjacent forelands on the Macao Peninsula. Various Chinese and foreign design celebrities can conveniently communicate with each other on local culture and customs, carry out various creative and design activities in Macao. The extensive and profound Chinese traditional culture and the imported European art concept represented by Portugal can collide and blend. Rich soil for creation and innovation is

Chinese Classification No.: J0 J218.7 Document code: A. provided

However, the culture of gambling industry has been flourishing since Macao declared the legalization of gambling in 1847 , while the unique culture with world integration has been deviating. It is particularly important to improve Macao's cultural taste and rebuild the cultural image of Macao.

\section{CURRENT SituAtion OF THE DEVELOPMENT OF ANIMATION INDUSTRY IN MACAO AND RELEVANT REGIONS}

Cultural and creative industries have been incorporated into the important planning of the national development strategy in the process of mutual complementarity of Guangdong-Hong Kong-Macao Greater Bay Area and deepening cooperation and reform. Guangdong, Hong Kong and Macao jointly shape the humanities bay area. Canton Animation \& Comic Industry Association is the only provincial animation industry association composed of animation enterprises. After ten years of development, freckle-removing sales exhibition activities have become one of the most popular professional exhibitions with high degree of specialization in China, favored by professional exhibitors and professional purchasers. Hong Kong Literary Federation Association for Animation is currently the animation association with the most complete industrial chain and largest output value and the most brands, which is committed to professional exchanges between Chinese artists in the Mainland, Hong Kong and abroad, covering animation works from multiple perspectives and fields. Macao Animation and Culture Industry Association, registered in Macao Special Administrative Region on July 18, 2007 , has carried out a number of thematic animation industry exchange activities, and participated in large-scale animation activities at home and abroad. It hosts the largest comprehensive animation exhibition in Macao every year. China (Shenzhen) International Cultural Industry Fair (ICIF) is known as "the first exhibition of cultural industry in China". There are more than 2300 enterprises participating in the exhibition every year and more than 100,000 project products displayed and traded here. ICIF has special exhibition areas in Hong Kong and Macao, highlighting the special relationship between the three regions in culture. The animation section in the exhibition is very adaptive to all aspects of teenagers and the public life, and integrates the excellent traditional Chinese cultural values into the popular expression forms of animation.

"ACG Carnival of Animation 2010", sponsored by the Macao Animation and Toy Game Chamber of Commerce, was 
officially launched at the Golden Light Convention \& Exhibition Center of the Venetian Macao Resort Hotel. A mature and systematic industrial chain has formed in the cartoon industry in this special area. Management agencies have not only issued a series of policies to encourage the development of the animation industry, and gave unprecedented policy support to the animation industry, but also accelerated the construction of various animation industry bases, animation teaching and research bases, animation revitalization bases, animation and cartoon, animation theme exchange and so on. The recruitment of animation talents will flourish everywhere, and there is a huge market in Macao's animation industry.

Sands China Ltd. adjacent to Macau University of Science and Technology, has cooperated with U.S. DreamWorks to transfer the animation copyright images of Kung Fu Panda, Monster Shrek, Madagascar and How to Train Your Dragon to the Cotai Strip Resorts in Macao. Meanwhile, Venetians are determined to integrate animation elements into a series of business activities. Visitors can choose to have breakfast with animation figures and tour together, and create a variety of animation derivatives.

New era animation, international film and television animation brand invitation exhibition, animation technology application experience exhibition, derivative IP business ecological exhibition and others are being held one after another and gradually embedded in the details of citizens' lives, making Macao's animation art develop very fast, attracting more and more attention.

\section{PROBlems IN THE CURRENT DEVELOPMENT OF MACAO'S ANIMATION INDUSTRY}

In 2012, the Macao Animation Alliance is composed of the Association of Cartoonists, the Cartoon World Studio, the Red Leaf Animation Association, the Macao Animation Cartoonists Association, the St. Lazarus Parish Creative Industry Promotion Association, and the newly added Macao Amateur Cartoon Society. The presidents of the six associations are the core members of the alliance, and Huang Yihui is elected as the Secretary-General of the alliance. However, after years of development, the brand works of Macao animation are still mainly imported. Good classic original films are scarce, and there is no special animation image or work with its own culture. The main reasons are as follows:

\section{A. Insufficient creativity}

Macao's investment in movies and TV programs mainly focuses on the introduction from abroad and variety shows, which makes animation producers pay too much attention to the line drawing, coloring and other production technologies, but lack early conception and creativity, as well as innovative original works. Even a few films with strong local culture have been promoted and shared on the platform at the Chinese and foreign exhibitions. Lighthouse (Deng Ta), Starry Night(Xing Ye), Dad's Lunch (Ba Ba De Wu Can), Peninsula Master's Grandma (Ban Dao Shi Nai), Electric Dirty (Dian Zang) and other works are displayed in China and the West, but they are all produced in a small scale, and there are still many defects in shotting and modeling.

\section{B. Lack of brands}

It is also an indisputable fact that Macao's animation lacks well-known independent brands. Despite the introduction of many animation brands and activities in various casinos, there are few animation works belonging to Macao people. This problem is related to the difficulty in mobilizing local market and domestic demand. Any industry must be based on the local market in order to gradually expand outward. The foundation may collapse in case of losing the local market. Macao animation has been living in the gap between American animation and Japanese animation, let alone the promotion of animation derivatives.

\section{Insufficient Training of Talents}

Macao's higher education with multiple cultures converged has started late, but developed rapidly, forming a unique education system. With the establishment of the Private University of East Asia in 1981, in 1988, the Macao Foundation changed the University of East Asia from private to public and renamed it as the University of Macao. The Graduate School and the Open School of the University were divided into City University of Macau. The university's Polytechnic Institute was planned to be Macau Polytechnic Institute. Meanwhile, Macau Polytechnic Institute was founded in 2000. At present, the two universities have doctoral programs in communication and design. The structure of the tutorial team is reasonable, showing the characteristics of sufficient teaching and experience, strong academic ability, and advanced teaching equipment.

Animation industry is an industry with high technology contents, high investment and long payback period. Despite Macao's rich cultural resources and development potential, Macao lacks relevant digital and animation technology investment and talent training mechanism. As of 2018, Macao has not set up animation-related majors in universities, which fully illustrates that the relevant departments' attention to and investment in animation education need to be improved, which is the fundamental reason why Macao's animation industry lags behind.

\section{REFLECTIONS ON THE DEVELOPMENT OF MACAO'S ANIMATION INDUSTRY AND TALENT TRAINING}

In view of the strong intersection of culture, art and technology of animation major and the geographical advantages of the integration of Chinese and Western culture in Macao, the author tries to put forward a series of ideas for your reference and correction.

\section{A. Introducing Macao's Industrial Characteristics and Reforming the Teaching Contents of Higher Education Majors}

Science and technology constitute the primary productive force, while innovation is the essential core of productive force. Firstly, the teaching objectives and methods of basic courses related to art majors in some colleges and universities can be 
adjusted accordingly to meet the needs of creative animation design, such as sketch, color, pattern and composition courses, which can be transformed and derived to the direction of creative hand-drawing, creative thinking training, animation characters, scene creativity, script creativity, animation material creativity expression and other contents. Secondly, more attention should be paid to the evaluation criteria of the preliminary design schemes of animation design, and the comprehensive application of image innovation, artistic expression and visual judgment. Attention should be paid to the application-oriented and technology-based curriculum education related to animation modeling design. It is because Macao's animation designers have a very good professional tradition, focusing on the relationship between animation modeling product design and products, are good at animation design, skilled in process, fashion and marketing, and have international brand vision and can control multi-department cooperation. If these skills are grafted into professional teaching, the teaching characteristics of Macao's animation major will be formed.

\section{B. Creating Macao Tourist Animation Culture Route Based on Community and Museum}

As Macao has experienced more than 400 years of extraordinary course, there are unique cultural phenomena that are incomparable in other regions. For example: cultural process of Chinese and Western differences and blending, unique architecture, cultural heritage and historic sites, extraordinary tourist routes, as well as attractive cuisine, charming customs, and passionate people. More interesting and elegant gambling arenas and so on are all the materials of animation scripts enthusiastically searched for, so as to create suspense-ridden, plot engaging works. Macao is one of the cities with the most international cultural blending characteristics in China. Stories produced by Macao are told in the form of animation and favored by Chinese people and people all over the world love to see and listen.

Let Macao's legendary history, amusing and interesting travel stories, thrilling gambling experiences, eye-opening museums and community stories, stunning tasteful food and performances and other special things and scenes of Macao presented to the world one by one through Macao as an unrestrained bridge, which will surely astound the viewers. It will be a win-win situation between Macao itself and Macao animation.

\section{Creation of Animation Images Based on Religion and Ethnic Groups}

The religious scene in Macao can be described as "God and Buddha everywhere". Confucianism, Buddhism, Taoism and other Eastern religions, as well as Catholicism, Christianity, Islam and other Western religions, and many temples of Guangong and Mazu in the Macao community are all over Macao, with many worships in the family. The diversity of religious culture has been fully reflected in Macao. The believers of these religions come from complex ethnic groups. The majority of them are Cantonese and Chaoshan, Hakka and Fujian people. The number of native Portuguese is small, but it is the dominant ethnic group of Macao. In addition, the gathering of overseas Chinese from all over the world has also brought the sacredness of their beliefs to Macao, which has led to the unique phenomenon of the coexistence of various religions and cultures in Macao. The poetry writing of Macao festival activities expresses Chinese poets' observation and description of the coexistence of Chinese and foreign cultures in Macao from their respective perspectives. It is not only a historical record, but also a kind of expression of the soul. It has become an integral part of Macao culture.

Religions belong to a cause-and-effect education for being rewarded for being benevolent to people. They pay attention to people who have faith and are always in a healthy and good mood, so as to firmly integrate human spiritual pleasure and belief. They are spread in the form of animation, more innovatively and effectively. At present, religious organizations all hope to use animation as a carrying boat to educate believers more effectively and to communicate with the masses to popularize their values and morals, which can naturally construct the corresponding religious cultural space of animation, thus promoting the revitalization and development of the animation industry with Macao's religious characteristics.

\section{CONCLUSION}

At present, the Macao Cultural Bureau has listed eight key development projects of cultural and creative industries, namely visual arts, design, film and video, pop music, performing arts, publishing, clothing and animation. The animation industry is regarded as the focus of development.

The whole story of Detective Conan Movie takes place in Kyoto, Japan. The unique buildings in Kyoto, beautiful cherry blossoms and songs composed of names of places along ten major roads from north to south become the clue of the film. With the popularity of domestic animated cartoon "The Story of Hongmao and Lantu", many people remember Zhangjiajie, Hunan Province. Annecy Festival of France (Festival International du Film d'Animation d'Annecy) attracts worldwide audiences and exhibitors every year, providing an important animation industry with cultural backing for the local economy. Identity and homogeneity will be replaced by pluralism, and a single culture will be surpassed by open culture. As a result, many excellent international animation works have been created to achieve worldwide dissemination effect. As an open area with highly developed economy, Macao should vigorously develop the most active and fashionable modern animation culture and art industry, complementing with Macao's higher education and tourism, making mutual benefit, accelerating people's understanding of Macao and making them love Macao.

\section{ACKNOWLEDGMENT}

About the author:

Ma Nan, Ph.D. in Design Theory and Practice, Grade 2015, School of Humanities and Arts, Macau University of Science and Technology. 


\section{REFERENCES}

[1] Wei Qingyuan Collection of Chinese Archives of Macao in the Qing Dynasty in Portuguese East Pota Archives Preface [J]. Historical Archives, 1998

[2] Zhang Junzhu. "Cultural Macao" Image-building and Promotion Strategy [J]. Furniture \& Interior Design, 2018.

[3] On July 15, 2005, the 29th meeting of UNESCO World Heritage Centre, The World Heritage List.

[4] News on February 18, 2019, the Central Committee of the Communist Party of China and the State Council issued the Development Plan for Guangdong-Hong Kong-Macao Greater Bay Area, http://www.xinhuanet.com/.

[5] Wang Xiwen, Deng Junjie On the Poetry Writing of Macao Festival Culture [J]. Writing, 2019.

[6] Macao opens the door of cultural and creative industries to the world [J]. Economic \& Trade Update, 2011.

[7] Gao Mingzhen, Xie Qianwei An Analysis of Internationalization Narration of Pixar Animation Films [J]. Movie Literature, 2018. 